The observations of galactic rotation throw some light on the question of the reality of the local cluster discussed by Dr. Brück. Rotational shear in such a cluster would be expected to spread it into a ringcertainly a cluster having the shape of a flattened ellipsoid of revolution would be unstable in a rotating galaxy. This objection is quite independent of theory : it is an observational fact that shear exists in the neighbourhood of the sun, hence that any local cluster must be at best a transitory phenomenon. This view is supported by observations of the cosmic cloud. The interstellar atoms and molecules responsible for stationary lines in stellar spectra are widely distributed throughout the Galaxy and show the same galactic rotation effect as the mean of the stars. It can be shown that these interstellar particles must move with velocities corresponding to circular orbits, otherwise impossibly large density gradients would be set up; hence the stars, too, are so moving, and any local cluster could not persist. From this point of view Sir Arthur welcomed Oort's hypothesis as a way of avoiding the dynamically unstable singularities involved in the hypothesis of a local cluster.

The discussion was wound up by the Astronomer Royal, Dr. H. Spencer Jones, who took as his subject the rotation of extra-galactic nebulæ and their internal distribution of mass. Pointing out that the planetary-type rotation described for our own Galaxy by Sir Arthur Eddington referred only to the solar neighbourhood, presumably at about 10,000 parsecs from the centre, Dr. Spencer Jones turned to spectroscopic observations of the rotation of other galaxies. These referred until recently only to the bright central portions of such objects as $N G C 4594$ and 4111 , the rotation of the nuclear regions of which is of the 'solid' type giving constant angular velocities.

Within the last few years, however, work at the Lick Observatory has made available rotational velocities for the Andromeda nebula ( $M$ 31) and $M 33$ out to considerable distances from their centres. The results of Babcock for $M 31$ show a period for the core of $11 \times 10^{6}$ years, and for the main body of $92 \times 10^{6}$ years, and indicate that much of the mass is in the outer regions. In $M 33$ Mayall and Aller find that the velocity increases at first linearly with radial distance from the centre, then faster until at the edge of the main body a maximum velocity is reached corresponding to a rotation period of $59 \times 10^{6}$ years. In the outer parts the velocity decreases again, the corresponding periods varying from 60 to $200 \times 10^{6}$ years. In these regions Oort's rotational "constant" $A$ varies from $84 \mathrm{~km}$. $/ \mathrm{sec}$./kpc. at 1,280 parsecs from the centre to $30 \mathrm{~km}$. $/ \mathrm{sec} . / \mathrm{kpc}$. at 1,920 parsecs, a rough extrapolation indicating that at about 2,200 parsecs conditions of rotation similar to those in the solar neighbourhood would be reached. This in turn indicates that if $M \mathbf{3 3}$ and our own Galaxy are comparable bodies, the sun is at a distance from the centre of at least twice the radius of the main body, and that from an external galaxy the main body would appear only about 8,000 parsecs in diameter, the sun being well beyond this in the thin outer regions. The observed distribution of rotational velocity in both $M 31$ and $M 33$ can be adequately represented by a thin-disk model, possessing circular symmetry, the individual parts of which revolve in circular orbits about the centre in the plane of the disk. Assuming that in such a disk the surface density can be expressed as a fifth-degree polynomial in the distance from the centre, Wyse and Mayall have determined the curves of force and thence of rota- tional velocity for typical disks. Then by working backwards they deduce the density distribution in $M 31$ and $M 33$ necessary to fit the observed velocity curves.

A wide distribution of mass throughout both systems is indicated, little tendency being found towards the central condensation usually postulated for our own Galaxy. In $M 31$, for example, the model of best fit consists of two concentric thin disks, and indicates that less than 1 per cent of the mass is contained in the central regions. The total mass is $9.5 \times 10^{10}$ suns, which agrees well with that of the Galaxy. A rediscussion of Oort's constants of galactic rotation shows that the information they yield concerning the distribution of matter in the Galaxy, while consistent with strong central condensation, does not lead uniquely to such condensation. It may well be, then, that the mass of the Milky Way system resides largely in its outer regions, in which the sun lies. The question then arises, Why should the brightness of a galactic system be so much less in the outer regions than near its nucleus? Can it be that the luminous giant stars occur near the centre while dwarfs tend to preponderate in the outer regions ; or is non-luminous dust so widespread round the periphery that it contributes much of the total mass of the Galaxy? These and many other questions of galactic structure must await further observations in happier times.

\section{BRITISH ASSOCIATION CONFERENCE ON MINERAL RESOURCES}

$\mathrm{T}$ HE Conference on Mineral Resources and the Atlantic Charter, held at the London School of Hygiene and Tropical Medicine on July 24-25, was convened by the British Association Division for the Social and International Relations of Science and, like the recent conference on agriculture, owed its origin to suggestions made at the Conference on Science and World Order held last September. The fourth clause of the Atlantic Charter promises equal access on the part of all peoples to the natural resources of the world, and as minerals are among the most important of those resources, it was felt that a survey of the situation might clarify ideas; the general state of information as to the distribution and nature of mineral deposits among the public and even, it is to be feared, in higher quarters, being very imperfect. Coal and oil were excluded from the scope of the discussion as requiring separate treatment. Those who have had occasion to examine questions concerning mineral deposits have been impressed by the unsatisfactory condition of the statistical knowledge about them which is available, in spite of excellent isolated efforts, and for that reason prominence was given to this aspect in the resolution which was put by Sir Stafford Cripps and passed at the end of the Conference. After a preamble referring to the Atlantic Charter, this ran :

"This Conference, having specifically dealt with mineral resources, submits that, as a first step, the Council should initiate forthwith consultations with appropriate scientific and technical organizations, to secure an understanding on the principles involved. The Conference would further urge that a scientific 
review of mineral resources, using and supplementing all existing data, should be among the first tasks of any international organization for the social applications of science, such as was envisaged at the recent Conference on Science and World Order. To this end, the Conference recommends that the Council should consider how it might help to promote the establishment of an International Resources Organization, as a fact-finding and advisory body for Governments, as a contribution to world stability, and in the spirit of the Atlantic Charter."

The Conference, which was well attended, was opened by the president of the Association, Sir Richard Gregory, who referred briefly to the new industrial revolution brought about some sixty years ago by the introduction of alloy steels, bringing unfamiliar metals into prominence; metals which are most unequally distributed in the crust of the earth, and thus having special significance in the light of the Atlantic Charter. Sir Thomas Holland, whose presidential address at the South African meeting of the Association first directed attention to the international importance of this irregular distribution of economic minerals and its bearing on preparations for war, then took the chair.

As examples of the questions to be considered, Sir Thomas Holland mentioned that the United States, with its vast steel industry, consuming 750,000 tons of manganese ore in 1937, was unable even with the help of a 100 per cent protective tariff to produce from home sources more than 5 per cent of her own requirements. Germany, also lacking manganese. was tempted by the great resources of South Russia in that metal, perhaps more than by petroleum, Great Britain was almost self-sufficient for the few and simple essential constituents of steel until the last quarter of the nineteenth century, but found itself dependent on distant parts of the Empire and on foreign countries for the alloying elements now needed. Unlike some other natural products, metals cannot be made synthetically for industrial use, and although for certain minor purposes they may be replaced by plastics, they remain indispensable to industry. This dependence necessitates the international exchange of minerals, and if this is to be facilitated, as it must be in a peaceable world, the knowledge of their distribution must be both more complete and more widely diffused.

Prof. H. H. Read, after apologizing to the many geologists present for his elementary treatment of the subject, gave a lucid account of the geological conditions which determine the distribution of mineral deposits. National boundaries have paid little attention to geological regions, and impossible demands for autarky have been made by dictators ignorant of their countries' geology. An autarky based, like that of the U.S.S.R., on a proper estimation of native resources is one thing, and an autarky based on legislation quite another. Even such a wide grouping as that of the United Nations is not completely selfsufficient in minerals, and still less any single country, however extensive.

It was natural that several of the speakers, who had prepared their papers independently, should select the metals used in the production of alloy steels as typical illustrations of irregular distribution. Prof. C. B. Fawcett, speaking of key metals and the location of industry, pointed out that these exceptional elements, such as tungsten, molybdenum and vanadium, are mainly found in the older rocks and for the most part in thinly populated areas. The quantities required are small in proportion to the tonnage of steel produced, and it is also characteristic of them that they pass entirely into the finished product, the loss in manufacture being almost negligible. Many of them occur in such a form that the ores have to be submitted to some kind of concentration before extraction. They are mainly consumed in the regions where heavy industries of the more advanced type are situated; industries employing much skilled labour. These are usually regions of long-established industry, and the gravitation to them of the key metals tends to confirm the existing location of those industries. A dominant fact is that they are essential to the production of armaments and to the making of tools used in that production, so that under existing political conditions no State can feel secure unless it has within its borders a considerable armaments industry. The importance of recovered or scrap metals, dealt with by later speakers, further tends to anchor the highly developed industries to their existing locations.

Prof. P. G. H. Boswell, dealing with the need for better and more complete statistics, reviewed the available sources of information and referred to the lack of uniformity in the definition of available resources. Much information about known resources and estimated reserves is locked up in the archives of mining companies, and it is a question how far this may be made available. An international commission seems to be the only body which could undertake the work after the War, and a useful beginning could be made even now if finance were provided. Exploration has now covered the greater part of the earth's surface, at least so far as the commoner minerals are concerned, but China still affords a vast field for further exploration, while the search for the rarer elements has been far less thorough.

Prof. Boswell concluded with a warning that the diversion of many geologists during the War to other activities, coming after a period in which the number of men being trained in geology was declining, may lead to a serious situation. British geologists have played a leading part in exploration, and many of the leading geologists of other countries have received their training in Great Britain ; the lack of appreciation of the importance of the subject, due to ignorance, calls for the attention of educational authorities. After the War, it may be necessary to provide geologists not only for our own needs, but also for loan to countries where scientific training has been interrupted or destroyed. In the course of the discussion it was suggested that geologists might be attached to legations in the lesser-known countries.

The afternoon session on July 24 was presided over by Sir William Larke, who also emphasized the need for a uniform basis for statistics and the fact that in spite of the British lead in scientific discovery and technical achievement, the nation as a whole lacks appreciation of the value of research. The need for continued inter-allied co-operation in this field and in that of economics was stressed. He alluded to the growing importance of the light metals and to the possibility of extracting aluminium from clay, thus rendering the industry less dependent on the very local distribution of bauxite. The high consumption of power in aluminium production would seem to determine the location of the industry, although for reasons partly economic and partly strategic Germany has built up an important aluminium industry based 
on electric power generated from brown coal and largely imported bauxite. Like other speakers, he referred to the key nature of the less common metals, large stocks of which had been accumulated by Germany before the War, while no doubt much has been done to conserve those resources by changes in the composition of alloys and in technique.

The remainder of the session was taken up by papers illustrating the general principles by reference to particular metals. Prof. W. R. Jones selected tin, the occurrence of which in useful quantities is confined to a very few regions. The United States consumes 40 per cent of the world's tin, but has not a single tin mine within its borders. Europe provides only 1 per cent of the world's output, this coming mainly from the anciently worked Cornish mines. The alluvial deposits which were the principal source of tin are being rapidly worked out, and we shall in the future be more and more dependent on lode mining. The conditions for the formation of lodes are confined to a few of the older rocks. More efficient concentration of the ores will become important.

Closely allied to the occurrence of tin is that of tungsten, the position of which was outlined by $\mathrm{Mr}$. J. L. F. Vogel. The geological conditions of the deposition of tungsten ores are such that no mining engineer would venture to predict the quantity to be found in a newly discovered deposit. The metal was actually the first to be used in the production of an alloy steel, Mushet having introduced it into his improved tool steel, and it was the main constituent of the high-speed tool steels which attracted so much attention at the Paris Exhibition of 1900. Until 1914 the production of the metal was mainly in Germany, although much of the ore occurs within the British Empire, but since then it has been produced at home.

Manganese ores, which are essential to steel making, were dealt with by Sir Lewis Fermor, who said that whereas manganese is only present in the earth's crust to the extent of 0.10 per cent of the oxide, the ores which are used as its source contain 40 per cent or more of the metal. Of the producers, the U.S.S.R. accounts for well over one-half of the world's supply of almost five million tons, India ranking second. The geographical distribution of this and other economic minerals was illustrated by maps showing the extent of the former continent of Gondwanaland. Ninety per cent of the total production of manganese is consumed in the iron and steel industry, and no satisfactory substitute for it has been found. The paper contained a number of valuable tables, and it was argued, on the basis of statistics of imports and exports, that the Axis countries had no real grievance in respect of supplies of manganese ore. Whereas they produced less than 2 per cent of the total, the pre-war system of international commerce allowed them to secure 26 per cent of the available exports, or 16 per cent of the world's production.

Nickel was discussed by Lieut.-Colonel the Hon. Colin A. Campbell. The greater part of this metal is also consumed in the iron and steel industry, for which it is essential for many purposes, including the stainless steels. Its occurrence is extremely restricted. The first extensive production was from New Caledonia, where it was discovered fifty years ago. The ore, garnierite, is a silicate. The far more extensive deposits of Sudbury, Canada, where the ore is a sulphide associated with copper, were discovered in 1887 and now provide 85 per cent of the total production. The other deposits of the world were reviewed, and even allowing for the opening up of new mines, it seems likely that Canada will account for 80 per cent of the total during our lifetime. The demand is certain to increase as the area of industrially developed countries is widened and their standard of living raised. Its extensive use in armaments gives it high importance in any scheme of sanctions against aggressors.

The last metal dealt with in the session was aluminium, a paper on which was contributed by Mr. M. P. Fogarty. The world output of virgin aluminium was approximately doubled between 1937 and 1941, reaching just under a million tons and it may reach $1,750,000$ tons by the end of this year, mainly owing to large extensions in the United States. Secondary aluminium recovered after use is now also an important factor in the industry. The paper dealt largely with the British industry after the War, and contained many statistical data and tables. The utilization of aluminium for civilian purposes has not proceeded so far as might have been expected, but its development is likely to be resumed as soon as the large amount consumed in the aircraft industry is released. An interesting review of new technical methods of utilizing the special qualities of the light alloys was included in the paper.

(To be continued.)

$$
\text { C. H. DEsch. }
$$

\section{OBITUARY \\ Mr. G. C. Lloyd}

Mr. George Christopher Lloyd, secretary of the Iron and Steel Institute during 1909-33, who died on July 10 at the age of eighty-one, was trained as an engineer, and after completing his apprenticeship spent some years with the Spanish Compañia Transatlantica. He had been at school in Germany, and the knowledge of languages which he gained in his studies and travels was a great asset to him in his later activities.

After a period in a firm of consulting engineers, he joined the staff of the Iron and Steel Institute as assistant to the secretary, but four years later left to become secretary of the Institution of Electrical Engineers. On the death of Mr. Bennett H. Brough he returned to the Iron and Steel Institute, which he served efficiently and devotedly for twenty-four years. Through the foreign meetings of the Institute he made friends among the metallurgists of many countries and was associated as secretary with several international congresses, being a vice. president of the International Association for Testing Materials. His services in this field were recognized by the conferment on him of the Swedish Order of the North Star and of the French Legion of Honour.

In 1915 he was also appointed secretary of the Statistical Bureau of the Iron, Steel and Allied Trades Federation, and for several years was responsible for the collection of statisties and their incorporation into an annual report. In 1918, at the instance of the Advisory Council for Scientific and Industrial Research, he prepared the first edition of a report on the sources and production of iron and other metalliferous ores used in the iron and steel industries of the United Kingdom.

To metallurgists in Great Britain and abroad $\mathrm{Mr}$. Lloyd's knowledge, courtesy and kindliness were well known; to the staff of the Iron and Steel Institute he was a valued friend. 